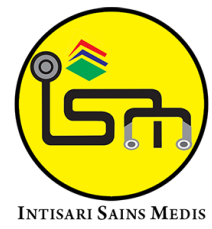

Published by Intisari Sains Medis

\section{Gambaran neurogenic bladder pada pemeriksaan voiding cystourethrography: serial kasus}

\author{
Kadek leke Sugeng Kurniawan ${ }^{1 *}$, Nyoman Srie Laksminingsih ${ }^{2}$, Firman Parulian Sitanggang ${ }^{3}$
}

1PPDS-1 Radiologi, Fakultas Kedokteran Universitas Udayana-RSUP Sanglah Denpasar, Bali-Indonesia; ${ }^{2}$ Divisi Abdomen (Urogenital dan Gastrointestinal), Departemen/KSM Radiologi, Fakultas Kedokteran Universitas Udayana-RSUP Sanglah Denpasar, BaliIndonesia;

${ }^{3}$ Divisi Radiologi Intervensi, Departemen/KSM Radiologi, Fakultas Kedokteran Universitas UdayanaRSUP Sanglah Denpasar, Bali-Indonesia;

\section{*Korespondensi:}

Kadek leke Sugeng Kurniawan;

PPDS-1 Radiologi, Fakultas Kedokteran Universitas Udayana-RSUP Sanglah Denpasar, Bali-Indonesia; dr.sugengkurniawan@gmail.com

Diterima: 18-08-2021

Disetujui: 02-10-2021

Diterbitkan: 22-10-2021

\section{ABSTRACT}

Background: Neurogenic bladder is a bladder disorder caused by any damage or disease that attacks the nervous system in the lower urinary tract. Neurogenic bladder is a complex process that requires thorough history taking, physical examination, and supporting radiology examination in determining the diagnosis of the disease. The voiding cystourethrography (VCUG) is radiological imaging that has an essential role in establishing the diagnosis of the neurogenic bladder. It also helps in determining therapy and preventing further complications. This case series aims to elaborate on three neurogenic bladder patients focusing on voiding cystourethrography and the etiology and complications concerning the disease.

Cases: The first patient was a 13-year-old girl with clinical neurogenic bladder and vesicoureteral reflux (VUR). The radiograph from VCUG examination revealed UMN type neurogenic bladder with chronic cystitis, left vesicoureteral reflux (VUR) grade V, partial obstruction in the left $1 / 3$ distal ureter at UVJ level, spina bifida in the $L 4$ vertebral body, and sacralization at L5. The second patient was a 7-month-old boy with clinical manifestations of urinary tract infection. The results of the VCUG examination found a neurogenic bladder of the UMN type with a posterior urethral valve accompanied by cystitis and diverticulosis. The third patient was a 34-year-old man with clinical features of urethral stricture. On VCUG examination, total stricture of the urethra pars membranacea, neurogenic bladder UMN type with cystitis and posterior bladder wall diverticula, and multiple vesicolithiasis were found. Conclusion: VCUG examination plays an important role in diagnosing neurogenic bladder and several etiologies and complications that can accompany it. In addition, optimal patient management and better prognosis can be achieved.

Keywords: bladder, neurogenic bladder, nervous system, radiology.

Cite This Article: Kurniawan, K.I.S., Laksminingsih, N.S., Sitanggang, F.P. 2021. Gambaran neurogenic bladder pada pemeriksaan voiding cystourethrography: serial kasus. Intisari Sains Medis 12(3): 763-767. D01: 10.15562/ism. v12i3.1144

\title{
ABSTRAK
}

Latar Belakang: Neurogenic bladder (kandung kemih neurogenik) adalah suatu kelainan pada kandung kemih yang disebabkan karena terdapat kerusakan maupun penyakit yang menyerang sistem saraf pada daerah inervasi saluran kemih bagian bawah. Neurogenic bladder merupakan suatu proses yang kompleks di mana diperlukan suatu proses anamnesis, pemeriksaan fisik dan pemeriksaan penunjang yang seksama dalam menentukan diagnosis penyakit tersebut. Voiding Cystouretrography (VCUG) merupakan salah satu pemeriksaan radiologi yang memiliki peran penting dalam menegakan diagnosis neurogenic bladder serta penentuan terapi dan pencegahan komplikasi lebih lanjut. Serial kasus ini akan membahas tiga kasus neurogenic bladder berdasarkan pemeriksaan voiding cystourethrography serta beberapa etiologi dan komplikasi yang dapat menyertainya.
Kasus: Pasien pertama yaitu wanita usia 13 tahun dengan klinis neurogenicbladder dan vesicouretericreflux (VUR). Pada pemeriksaan VCUG didapatkan neurogenic bladder tipe UMN dengan gambaran cystitis kronis, vesicoureteric reflux (VUR) kiri grade V, parsial obstruksi pada ureter kiri $1 / 3$ distal setinggi UVJ, spina bifida pada corpus vertebra $L 4$, dan sacralisasi pada $L 5$. Pasien kedua adalah laki-laki usia 7 bulan dengan manifestasi klinis infeksi saluran kemih. Hasil pemeriksaan VCUG didapatkan gambaran neurogenic bladder tipe UMN dengan posterior urethral valve disertai dengan cystitis dan divertikulosis. Pasien ketiga merupakan laki-laki usia 34 tahun dengan gambaran klinis striktur uretra. Pada pemeriksaan VCUG didapatkan striktur total urethra pars membranacea, neurogenic bladder tipe UMN dengan cystitis dan divertikel dinding posterior buli serta vesicolithiasis multipel. 
Simpulan: Pemerikasan VCUG memegang peranan penting dalam mendiagnosis neurogenic bladder beserta beberapa etiologi dan komplikasi yang dapat

Kata kunci: kandung kemih, neurogenic bladder, sistem saraf, radiologi.

Sitasi Artikel ini: Kurniawan, K.I.S., Laksminingsih, N.S., Sitanggang, F.P. 2021. Gambaran neurogenic bladder pada pemeriksaan voiding cystourethrography: serial kasus. Intisari Sains Medis 12(3): 763-767. D0I: 10.15562/ism. v12i3.1144

\section{PENDAHULUAN}

Neurogenic bladder (kandung kemih neurogenik) adalah suatu kelainan pada kandung kemih yang disebabkan kerusakan maupun penyakit yang menyerang sistem saraf yang menginervasi saluran kemih bagian bawah. Persarafan saluran kemih bagian bawah terbagi atas 3 set saraf periferal yaitu sistem persarafan parasimpatis (saraf pelvis), persarafan simpatik (saraf hipogastrik dan rantai simpatik thorakolumbal) dan persarafan sakral motorik (saraf pudendal). ${ }^{1,2}$ Manifestasi yang muncul pada neurogenic bladder dapat berupa kandung kemih yang tidak dapat berkontraksi dengan baik pada saat miksi (underactive bladder) maupun kandung kemih yang terlalu aktif berkontraksi dalam mengosongkan kandung kemiih (overactive bladder) atau gabungan dari kedua kondisi tersebut. ${ }^{3}$

Kelainan tersebut dapat merupakan bagian kelainan kongenital ataupun kelainan yang didapat. Neurogenic bladder pada anak berbeda dengan dewasa dalam hal etiologi. Sebagian besar neurogenic bladder pada anak disebabkan kelainan kongenital, sedangkan pada dewasa lebih sering karena kelainan didapat. ${ }^{3}$

Salah satu penelitian pertama mengenai prevalensi neurogenic bladder di Asia adalah sebuah survei yang dilakukan oleh Asia Pacific Continence Advisory Board (APCAB) yang mencakup 7875 laki-laki dan perempuan, dimana sekitar $70 \%$ adalah perempuan dari 11 negara termasuk 499 dari Indonesia, didapatkan bahwa prevalensi neurogenic bladder secara umum di Asia adalah sekitar 50,6\%. Neurogenic bladder akan meningkat jumlahnya pada kondisi neurologis tertentu. Sebagai contoh, neurogenic bladder di Amerika telah ditemukan pada $40 \%$ - 90\% pasien dengan sklerosis multipel, $37 \%$ - $72 \%$ pada pasien dengan parkinson dan $15 \%$ pada pasien dengan stroke. Kelainan kandung kemih sering dijumpai pada pasien dengan kelainan spina bifida, dengan angka pravelensi 1:1000 kelahiran hidup. Vesicourethra relux (VUR) dapat bermanifestasi pada hampir $40 \%$ pasien dengan spina bifida pada usia 5 tahun serta mencapai $61 \%$ pasien dewasa muda dengan spina bifida akan mengalamai inkontensia urine. ${ }^{3,4}$

Berdasarkan letak kelainan lesi pada sistem persarafan dan manifestasi klinis yang muncul pada pasien dengan neurogenic bladder, Lapides membagi kelainan neurogenic bladder menjadi 5 tipe, yaitu: (1) reflex neurogenic bladder, (2) in-inhibited neurogenic bladder, (3) autonomous neurogenic bladder, (4) motor paralytic neurogenic bladder, dan (5) sensory paralytic neurogenic bladder. ${ }^{5}$ Manifestasi klinis yang muncul pada pasien neurogenic bladder tidak selalu sesuai dengan klasifikasi yang dijabarkan oleh Lapides, karena kecenderungan lesi yang terjadi pada sistem persarafan tumpang tindih satu dengan kondisi lainnya sehingga manifestasi yang muncul pada pasien dapat bervariasi. Untuk mempermudah dalam mendeskripsikannya, neurogenic bladder dapat dibagi menjadi dua tipe berdasarkan letak lesi terhadap sacral reflex arch yaitu: upper motor neuron type ([UMN] untuk lesi di atas sacral reflex arch) dan lower motor neuron type ([LMN] untuk lesi pada dan di bawah sacral relex arch). Untuk lesi UMN biasanya bermanifestasi sebagi hiper-refleksi dari otot detrusor dan lesi LMN bermanifestasi sebagi arefleksi otot detrusor.

Radiologist memiliki peranan yang sangat penting dalam mendiagnosis dan mengevaluasi pasien dengan neurogenic bladder. Pada umumnya fase awal dari neurogenic bladder ditemukan pada saat melakukan pemeriksaan radiologis yang bukan bertujuan untuk mengevaluasi neurogenic bladder. Hal ini menjadi informasi yang penting bagi para klinisi untuk mendiagnosis dan merencanakan tatalaksana pasien dengan lebih cermat, sehingga komplikasi dari neurogenic bladder seperti infeksi saluran kemih berulang, pembentukan batu saluran kemih bahkan gagal ginjal dapat dicegah dan prognosis pasien menjadi lebih baik.

Berbagai pemeriksaan canggih dapat dilakukan untuk melalukan evaluasi terhadap disfungsi dari berkemih. Kombinasi voiding cystourethrography (VCUG) dengan studi urodinamik simultan (uroflowmetri, yang mengukur flow rate, peak flow dan flow pattern) dan elektromiografi (EMG) untuk melakukan monitoring aktivitas dari sfingter eksternal dilakukan dengan dilengkapi rekaman video serta audio untuk mengevaluasi proses pengisian dan pengosongan dari kandung kemih. ${ }^{6}$ Pemeriksaan ini sangat kompleks, menghabiskan banyak waktu dan mahal, dengan kondisi hanya sebagian kecil dari populasi dengan gangguan berkemih yang memerlukan pemeriksan lengkap tersebut. Dalam praktek sehari-hari, seorang radiologist dengan pemahaman yang baik tentang anatomi, fisiologi dan patologi dari saluran perkemihan dilengkapi dengan anamnesis pasien yang terarah, dengan pemeriksaan standar VCUG dapat menegakan diagnosis dari neurogenic bladder secara tepat.

\section{LAPORAN KASUS}

\section{Kasus 1}

Pasien perempuan usia 13 tahun dengan keluhan nyeri pada perut bagian bawah dan saat buang air kecil (BAK) sejak sekitar 3 bulan terakhir. Keluhan ini 
dirasakan hilang timbul disertai dengan ketidakmampuan pasien untuk menahan BAK. Sejak lahir hingga usia 13 tahun, pasien selalu menggunakan popok karena terkadang pasien masih mengompol. Pasien sudah sempat berobat ke rumah sakit dan dilakukan pemeriksaan ultrasonografi (USG). Berdasarkan hasil USG, terdapat infeksi ginjal dan ginjal kiri membengkak. Kemudian pasien melakukan pemeriksaan VCUG di RSUP Sanglah dan didapatkan gambaran: (1) neurogenic bladder tipe UMN dengan gambaran cystitis kronis, (2) vesicoureteric reflux (VUR) kiri grade V, (3) divertikulosis dengan tanda inflamasi
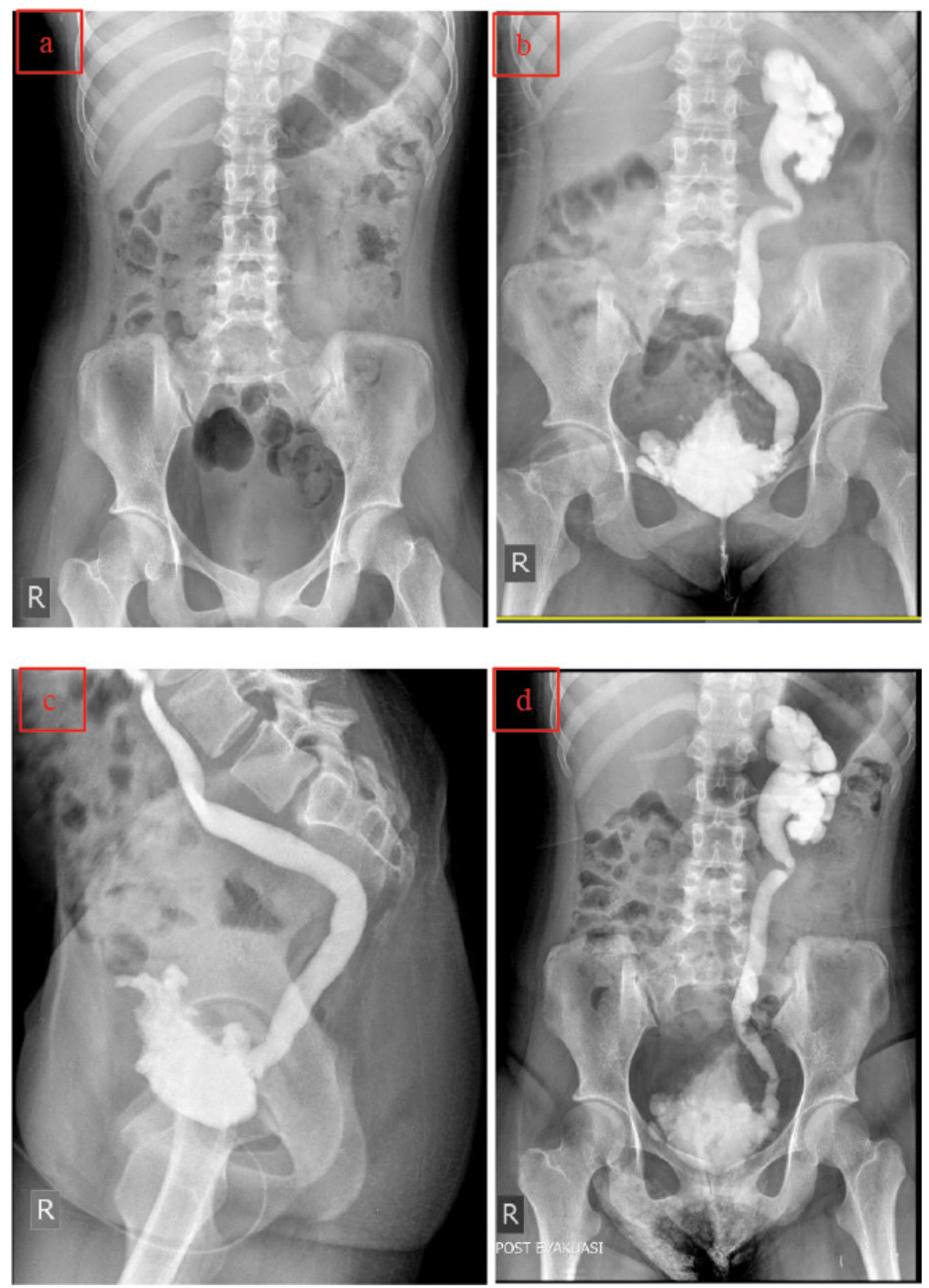

Gambar 1. (a) pencitraan foto polos menunjukkan spina bifida pada corpus vertebra L4, sacralisasi pada L5 dan parsial agenesis os sarcum dan agenesis os coxigeus; (b,c,d) VCUG (AP, lateral dan post miksi) tampak elongasi dan irregularitas dinding kandung kemih dengan gambaran christmas tree appearance (neurogenic bladder tipe UMN), VUR grade 5 dan divertikulosis.
Menurut orang tua pasien, pasien sudah berulang kali mengalami infeksi saluran kemih. Sebelum kunjungan, pada pasien telah dilakukan pemeriksaan USG urologi dengan hasil terdapat pembengkakan pada ginjal dan ureter kanan dan kiri. Pada kunjungan berikutnya, dilakukan pemeriksaan VCUG di RSUP Sanglah dan didapatkan gambaran neurogenic bladder tipe UMN dengan posterior urethral valve disertai dengan cystitis dan divertikulosis. Tak tampak gambaran VUR (Gambar 2).

\section{Kasus 3}

Pasien laki-laki usia 34 tahun datang dengan keluhan nyeri perut bagian bawah serta BAK bercampur darah sejak 3 hari yang lalu. Riwayat demam dan trauma saat pemeriksaan disangkal, namun sebelumnya pernah mengalami kecelakaan lalu litas tahun 2013 di mana kondisi bawah kandung kemih dan lambung sobek kemudian pasien dioperasi dan dikatakan sembuh. Pada tahun 2014 mengalami gangguan berkemih serta berkemih dibantu dengan selang. Pada tahun 2014 pasien melakukan operasi pemasangan selang di perut, dilanjutkan tahun 2015 pasien melakukan operasi perbaikan saluran kemih (urethroplasty) namun gagal dan kembali di pasang selang melalui perut untuk membantu berkemih. Pada pasien dilakukan pemeriksaan VCUG di RSUP Sanglah dan didapatkan striktur total urethra pars membranacea, neurogenic bladder tipe UMN dengan cystitis dan vesicolithiasis multipel (Gambar 3).

\section{PEMBAHASAN}

Menurut Shapiro et al. (1998), pasien dengan spina bifida (myelomeningocele) mengalami penurunan inervasi saraf periferal yang menuju kandung kemih, prostat dan rektum. ${ }^{7}$ Selain penurunan inervasi, terjadi juga gangguan pada jalur impuls parasimpatik. Neurotransmitter kolinergiksepertiadenosine 5'-triphosphate (ATP) dan neuropeptide $Y$ yang memiliki peranan integral dalam persarafan efferent menuju ke otot detrusor kandung kemih mengalami penurunan jumlah yang signifikan pada pasien dengan myelomeningocele dibandingkan dengan kelompok kontrol. ${ }^{1}$ Pada pasien pertama, melalui pemeriksaan foto polos ditemukan 

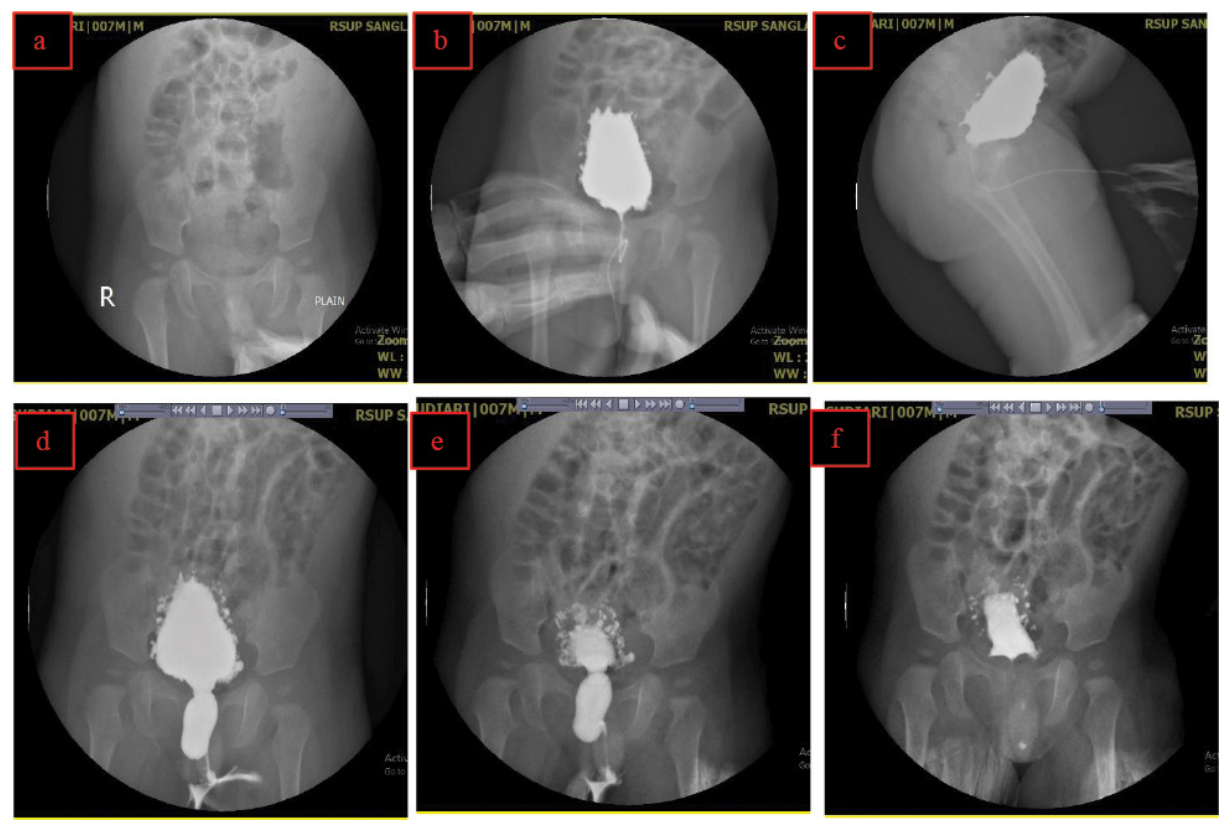

Gambar 2. (a) pencitraan foto polos; (b,c) VCUG (AP, lateral) Christmas tree appearance (neurogenic bladder tipe UMN); (d, e) VCUG (miksi) posterior urethral valve dengan gambaran keyhole sign dan (f) VCUG (post miksi) divertikulosis.

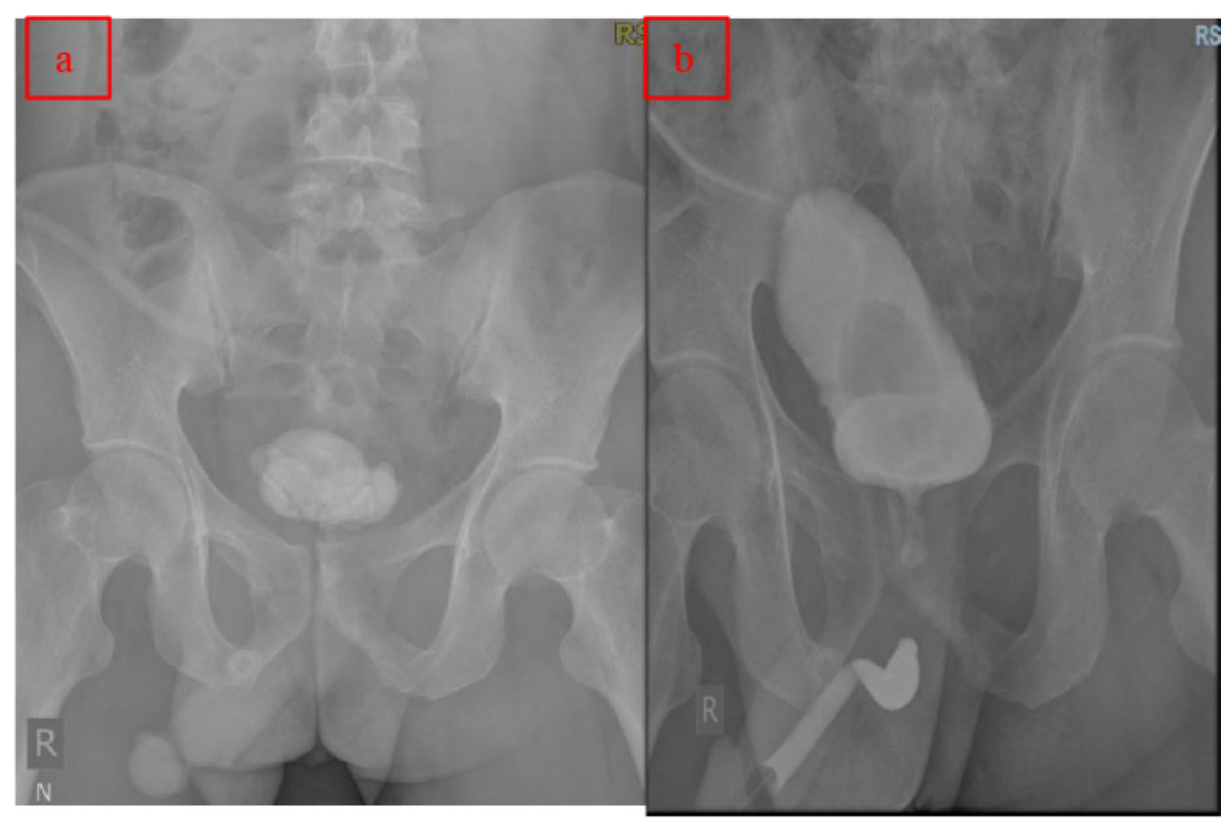

Gambar 3. (a) pencitraan foto polos menunjukan gambaran vesicolithiasis multipel; (b) VCUG memperlihatkan Christmas tree appearance (neurogenic bladder tipe UMN), striktur total urethra pars membranacea.

adanya spina bifida pada level L4. Hal ini akan memberikan gambaran neurogenic bladder tipe UMN karena lesi di atas level S2-4 akan menyebabkan impuls sensorik dan motorik dari dan ke kandung kemih akan terganggu disertai adanya disinergia detrusor-sfingter. Kondisi tersebut akan menyebabkan kandung kemih akan terisi terus dangan urine tanpa adanya sensasi ingin berkemih sehingga mengakibatkan tekanan intravesikal terus meningkat. Pada saat tekanan intravesikal mencapai tingkat tertentu, hal ini akan menyebabkan terjadinya kontraksi dari otot detrusor melalui refleks kontraksi involunter. Peristiwa ini dimediasi oleh sacral reflex arch yang berada di bawah level lesi meskipun tidak ada impuls eferen (motorik) dari pontine micturition center (PMC) ke otot detrusor. Karena adanya disinergia detrusor-spinter, pada saat terjadinya kontraksi involunter dari otot detrusor kandung kemih, sfingter uretra posterior yang seharusnya terbuka, tetap tidak terbuka. Keadaan ini akan menyebabkan terjadi gambaran radiologi berupa kandung kemih yang terelongasi ke proksimal dengan ujung yang meruncing disertai dengan trabekulasitrabekulasi karena adanya kontraksi otot detrusor memberikan gambaran pinecone bladder / christmast tree bladder. ${ }^{4,6}$ Pada pasien ini juga terjadi gambaran beberapa komplikasi neurogenic bladder, seperti vesicoureteric reflux (VUR) dan divertikula akibat tekanan intravesikal yang tinggi sehingga berimplikasi pada aliran balik dari urine menuju ke ureter dan ginjal dan cystitis akibat dari stagnansi urine pada kandung kemih yang merupakan media baik dari kuman untuk bertumbuh.

Katup posterior uretra (posterior urethral valve) adalah suatu kondisi dimana adanya membran pada uretra posterior yang terbentuk karena perkembangan abnormal pada saat intrauterine. Hal tersebut menyebabkan obstruksi outlet kandung kemih pada anak laki-laki. Pada pasien kedua dengan posterior urethral valve juga dapat memberikan gambaran pinecone bladder/ christmast tree bladder. Fenomena tersebut disebabkan adanya retensi urine sehingga kandung kemih menjadi terdistensi dan kontraksi otot detrusor dalam upaya untuk mengevakuasi akan menyebabkan trabekulasi pada kandung kemih. Selain itu, pada pasien dengan posterior urethral valve juga di dapatkan elongasi dan dilatasi dari uretra posterior yang menberikan gambaran keyhole sign.8,9 Gambaran cystitis dan divertikula pada pasien merupakan komplikasi akibat stagnansi urine dan akumulasi dari peningkatan tekanan intravesikal yang berlangsung kronik.

Pada pasien ketiga, adanya riwayat kandung kemih yang sobek saat terjadi 
kecelakaan lalu lintas, dapat menyebabkan ikut terputusnya persarafan yang menginervasi kandung kemih, baik pada jalur persarafan simpatik maupun parasimpatik. Hal ini dapat menjadi etiologi munculnya neurogenic bladder tipe UMN pada pasien. Selaian karena gangguan inervasi persarafan, adanya striktur uretra juga memiliki kontribusi dalam munculnya gambaran pinecone bladder/christmast tree bladder pada pasien. Striktur uretra yang terjadi karena riwayat pemasangan berulang kateter urine dan urethroplasty yang gagal pada pasien menyebabkan aliran urine yang tidak lancar sehingga memicu penumpukan urine pada kandung kemih dan berujung pada terjadinya distensi kandung kemih. Pada pasien ini juga didapatkan salah satu komplikasi yang bisa terjadi akibat neurogenic bladder, yaitu terbentuknya batu pada saluran kemih dalam hal ini adalah vesicolithiasis.

\section{SIMPULAN}

Neurogenic bladder adalah suatu kondisi yang kompleks pada pasien karena dapat disebabkan berbagai macam etiologi dan begitu pula komplikasi yang ditimbulkan olehnya. Metode VCUG merupakan suatu pemeriksaan radiologi yang memiliki peranan penting dalam membantu menentukan diagnosis neurogenic bladder. Seorang ahli radiologi dituntut untuk mampu memahami dengan baik pemeriksaan VCUG, sehingga dapat memberikan informasi yang tepat mengenai neurogenic bladder, etiologi serta komplikasi yang dapat menyertainya. Hal ini juga dilakukan agar pasien mendapat terapi yang tepat sehingga prognosis menjadi lebih baik.

\section{KONFLIK KEPENTINGAN}

Penulis tidak memiliki konflik kepentingan terkait publikasi dari artikel ini.

\section{PENDANAAN}

Laporan kasus ini tidak mendapatkan bantuan pendanaan dari sektor apapun.

\section{ETIKA DALAM PUBLIKASI}

Seluruh pasien telah menandatangani lembar informed consent dan menyetujui publikasi dari data medis mereka dalam jurnal ilmiah kedokteran dengan tetap menjaga kerahasian identitas.

\section{KONTRIBUSI PENULIS}

Kadek Ieke Sugeng Kurniawan bertanggung jawab dalam penyusunan naskah publikasi dan Nyoman Srie Laksminingsih serta Firman Parulian Sitanggang bertanggung jawab terhadap ekspertise radiologi dan supervisi penyusunan naskah publikasi.

\section{DAFTAR PUSTAKA}

1. Weiss DA, Lee AS, Flanders TM, Long CJ, van Batavia JP, Zderic SA, et al. Neurological dysfunction of the bladder from myelomeningocele. Neurosurgical Focus. 2019;47(4):1-8.

2. Dorsher PT, McIntosh PM. Neurogenic bladder. Advances in Urology. 2012.

3. Shenot PJ. Neurogenic Bladder - Genitourinary Disorders - MSD Manual Professional Edition [Internet]. 2020. Available from: https://www. msdmanuals.com/professional/genitourinarydisorders/voiding-disorders/neurogenicbladder

4. David Ginsberg MD. The Epidemiology and Pathophysiology of Neurogenic Bladder. Supplements and Featured Publications. 2013;19(10 Suppl). Available from: https:// www.ajmc.com/view/ace012_jul13_ngb_ ginsberg1_s191

5. Lapides J. Neuromuscular vesical and urethral dysfunction. In: Campbell MF, Harrison JH, editors, editors. Urology. 2nd ed. Philadelphia: WB Saunders; 1997. p. 1343-79.

6. Jafri SZ, Diokno AC, Amendola MA. Lower Genitourinary Radiology: Imaging and Intervention. New York: Springer Science \& Business Media; 1998. 547.

7. Shapiro E, Seller MJ, Lepor H, Kalousek DK, Hutchins GM, Perlman EJ, et al. Altered smooth muscle development and innervation in the lower genitourinary and gastrointestinal tract of the male human fetus with myelomeningocele. Journal of Urology. 1998;160(3 Part 2):1047-53. Available from: https://doi.org/10.1016/S00225347(01)62695-8

8. Berrocal T, López-Pereira P, Arjonilla A, Gutiérrez J. Anomalies of the Distal Ureter, Bladder, and Urethra in Children: Embryologic, Radiologic, and Pathologic Features. RadioGraphics. 2002;22(5):113964. Available from: https://doi.org/10.1148/ radiographics.22.5.g02se101139

9. Haller JO, Slovis TL, Joshi A. Abdominal Imaging. In: Haller JO, Slovis TL, Joshi A, editors. Pediatric Radiology: An Introduction for Medical Students, Residents, and Pediatric Health Care Providers. Berlin, Heidelberg: Springer Berlin Heidelberg; 2005. p. 85-152. Available from: https://doi.org/10.1007/3-54026442-6_5

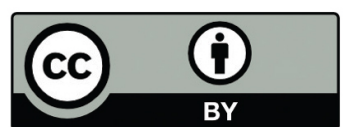

This work is licensed under a Creative Commons Attribution 